\title{
Drug selection for sedation and general anesthesia in children undergoing ambulatory magnetic resonance imaging
}

\author{
Sung Mee Jung \\ Department of Anesthesiology and Pain Medicine, Yeungnam University College of Medicine, Daegu, Korea
}

Received: March 16, 2020

Revised: March 29, 2020

Accepted: April 6, 2020

Corresponding author:

Sung Mee Jung

Department of Anesthesiology and

Pain Medicine, Yeungnam University

College of Medicine, 170

Hyeonchung-ro, Nam-gu, Daegu

42415, Korea

Tel: +82-53-620-3368

Fax: +82-53-625-5725

E-mail: applejsm@gmail.com
The demand for drug-induced sedation for magnetic resonance imaging (MRI) scans have substantially increased in response to increases in MRI utilization and growing interest in anxiety in children. Understanding the pharmacologic options for deep sedation and general anesthesia in an MRI environment is essential to achieve immobility for the successful completion of the procedure and ensure rapid and safe discharge of children undergoing ambulatory MRI. For painless diagnostic MRI, a single sedative/anesthetic agent without analgesia is safer than a combination of multiple sedatives. The traditional drugs, such as chloral hydrate, pentobarbital, midazolam, and ketamine, are still used due to the ease of administration despite low sedation success rate, prolonged recovery, and significant adverse events. Currently, dexmedetomidine, with respiratory drive preservation, and propofol, with high effectiveness and rapid recovery, are preferred for children undergoing ambulatory MRI. General anesthesia using propofol or sevoflurane can also provide predictable rapid time to readiness and scan times in infants or children with comorbidities. The selection of appropriate drugs as well as sufficient monitoring equipment are vital for effective and safe sedation and anesthesia for ambulatory pediatric MRI.

Keywords: Ambulatory; Anesthesia; Deep sedation; Magnetic resonance imaging; Pediatrics

\section{Introduction}

The prevalence of magnetic resonance imaging (MRI) for diagnosing and monitoring a wide range of disease in children continues to expand with the efficacy benefit of providing high-resolution images of tissue anatomy and quantitative function and the safety advantage of a lack of ionizing radiation $[1,2]$. Aspects of MRI scans such as loud noises, confined bore of the magnet, and the required immobility to prevent motion artifacts are the causes of anxiety and barriers to successful performance of the procedure in children younger than 6 years and those at any age with development delay, claustrophobia, or involuntary movements or con- vulsions. Given the increase in MRI utilization and growing interests in the pain and anxiety of children, the demand for drug-induced sedation during MRI scans have substantially increased over the past decade. Generally, pediatric MRI scans require deep sedation or general anesthesia to achieve absolute immobility (sometimes with breath-holding) for up to 1 hour (Table 1) [3-5].

The greater the level of sedation, the greater the risk for complications. In addition, it is common that the child easily progresses to a deeper level of sedation without easily recognizable signs. For these reasons, patients who require more than conscious sedation in an MRI suite must be provided with the same level of safety and monitoring (pulse oximetry, capnography, electrocardiogram,

Copyright (C) 2020 Yeungnam University College of Medicine

This is an Open Access article distributed under the terms of the Creative Commons Attribution Non-Commercial License (http://creativecommons.org/licenses/by-nc/4.0/) which permits unrestricted non-commercial use, distribution, and reproduction in any medium, provided the original work is properly cited. 
Table 1. Levels of sedation defined by American Society of Anesthesiologists

\begin{tabular}{lllll}
\hline Factor & \multicolumn{1}{c}{ Minimal sedation } & \multicolumn{1}{c}{ Moderate sedation } & Deep sedation & General anesthesia \\
\hline Responsiveness & $\begin{array}{c}\text { Normal response to verbal } \\
\text { stimulation }\end{array}$ & $\begin{array}{c}\text { Purposeful response to verbal } \\
\text { or tactile stimulation }\end{array}$ & $\begin{array}{c}\text { Purposeful response following } \\
\text { repeated or painful stimulation }\end{array}$ & $\begin{array}{l}\text { Unarousable even with painful } \\
\text { stimulation }\end{array}$ \\
Airway & No intervention required & Intervention may be required & Intervention often required \\
Spontaneous ventilation & Unaffected & Adequate & May be inadequate & Frequently inadequate \\
Cardiovascular function & Unaffected & Usually maintained & Usually maintained & May be impaired \\
\hline
\end{tabular}

Reprinted from "Continuum of depth of sedation: definition of general anesthesia and levels of sedation/analgesia" developed by the American Society of Anesthesiologists [5].

heart rate, and blood pressure at least 5 minutes interval by an independent observer) as in the operating room [6]. However, pediatric sedation in an MRI environment presents unique challenges that are not existent in the operating room. Powerful static and dynamic magnetic fields with radiofrequency pulses restrict the use of standard ferromagnetic anesthesia machines and monitoring equipment and limits access to the patients throughout the scanning process. Emergently halting MRI for patient safety takes several minutes to be effective and is expensive. In addition, adverse events including incoordination of movements, dizziness, and agitation occurs in $64.4 \%$ patients, and a return to baseline takes more than 9 hours after discharge in children undergoing MRI [4]. Thus, sedation providers should have an in-depth knowledge of drugs including a clear understanding of the sedating medication's pharmacokinetics and pharmacodynamics, drug interactions, and potential complications, as well as the presence of appropriate monitoring equipment and personnel with the skills needed to rescue a patient from adverse events for safe and efficient sedation for pediatric MRI.

This article reviews currently used sedative/anesthetic agents for deep sedation or general anesthesia for ambulatory pediatric MRI. The benefits and risks of deep sedation and general anesthesia are also included. In this article, the most commonly used drugs in Korea will be highlighted.

\section{Consideration in sedative/anesthetic regimen determination}

Selecting sedation or general anesthesia for MRI should be made on an individual patient basis, considering the benefits and risks. The goals of sedation or anesthesia for ambulatory pediatric MRI are as follows: (1) to guard the patient's safety and welfare; (2) to minimize physical discomfort and pain; (3) to control anxiety, minimize psychological trauma, and maximize the potential for amnesia; (4) to control movement to allow the safe and efficient completion of the procedure; and (5) to provide early, safe discharge from the hospital [6]. The ideal drug regimen to achieve these goals should have the following desirable characteristics: (1) rapid onset of action; (2) predictable duration; (3) easy titratability within the desired range of the sedation continuum; (4) rapid and consistent cessation of effects; (5) multiple delivery options; (6) a wide therapeutic window; (7) minimal cardiorespiratory depression; (8) minimal drug interaction; and (9) be minimally affected by renal or hepatic disease [7]. Generally, decisions regarding the drugs to be used for sedation depends on the patientrelated (neurodevelopmental status, underlying health condition, and previous sedation/anesthesia history) and procedure-related factors (degree of cooperation/immobility required, invasiveness, and duration). A single sedative/hypnotic without an analgesic is preferred for obtaining immobility for nonpainful MRI procedures [3]. A combination of two or more sedating medications may have the potential for adverse outcomes $[8,9]$.

\section{Drugs for deep sedation or general anesthesia for pediatric magnetic resonance imaging}

\section{Sedative/hypnotic agents}

1) Chloral hydrate

Choral hydrate is a sedative hypnotic agent with no analgesic properties. It is believed that its sedative mechanism is mediated by the $\gamma$-aminobutyric acid type $\mathrm{A}\left(\mathrm{GABA}_{\mathrm{A}}\right)$ receptor in the central nervous system. Chloral hydrate is well absorbed from the gastrointestinal tract via an oral or rectal route and rapidly metabolized into an active metabolite, trichloroethanol, which is responsible for its sedative and hypnotic effects. The onset of action is $30-60$ minutes and the duration of action is $60-120$ minutes. However, individual responses may be highly variable and sedative effects may last up to 24 hours. The half-life is age dependent and varies from 4 to 12 hours and may extend to 37 hours and 28 hours in preterm and term infants, respectively [10]. Thus, chloral hydrate has the potential for resedation after initial recovery from sedation and may produce residual effects up to 24 hours after ad- 
ministration.

Although it has little effect on the cardiovascular and respiratory systems, adverse events including nausea and vomiting, gastritis, diarrhea, prolonged sedation, paradoxical excitement, agitation, and minor respiratory depression should be considered. Children receiving chloral hydrate should be properly monitored and managed by appropriately trained personnel due to the risk of respiratory depression and desaturation especially in infants younger than 6 months $[9,11]$. It should be avoided in children with moderate to severe renal failure, severe hepatic dysfunction, hypersensitivity to chloral hydrate, gastritis, esophagitis, peptic ulcer, adenoid hypertrophy, and porphyria [12].

The recommended dose of chloral hydrate is $50-100 \mathrm{mg} / \mathrm{kg}$ (up to a maximum of $2 \mathrm{~g}$ ) [13]. The success rate of chloral hydrate sedation for pediatric MRI varies from 78\%-100\% [14-19] and is affected by the total dose administered, age, fasting status, and neurodevelopmental disability $[14,15,18,19]$. When 100 $\mathrm{mg} / \mathrm{kg}$ of chloral hydrate is administered, the sedation success rate was $96 \%$ in children under 48 months but decreased to $86 \%$ in those older than 48 months [20]. The United Kingdom (UK) National Institute for Clinical Excellence (NICE) also recommends the use of oral chloral hydrate with a wide margin of safety in children under $15 \mathrm{~kg}$. In contrast, chloral hydrate can be used as a first-line sedative agent for MRI in newborns and infants with the lowest risk of cardiorespiratory adverse events compared to phenobarbital and propofol $[17,21]$. Although there are no clear guidelines for pre-procedural fasting for chloral hydrate, fasted children require a greater dose of chloral hydrate, which is related to a longer onset and duration of action. Thus, children may be encouraged to take at least clear fluids 2 hours before the procedure for successful sedation without breaking institutional fasting protocols for chloral hydrate sedation [22]. Choral hydrate should not be used in children with neurodevelopmental disorders due to the increased incidence of adverse effects and decreased efficacy as compared with neurologically intact children [18]. In contrast, it may be used safely and effectively in properly monitored children who have congenital heart disease, including those with cyanotic heart disease, for painless diagnostic procedures [23].

Currently, both the United States Food and Drug Administration (FDA) and European Medicines Agency (EMA) have withdrawn the approval of chloral hydrate partly due to the potential risk of carcinogenicity. In conclusion, chloral hydrate seems to provide safe and effective sedation for children under 48 months old undergoing MRI. However, its use is progressively decreasing based on the high failure rate for MRI sedation, prolonged recovery time, and introduction of more effective sedative agents in many countries [24].

\section{2) Pentobarbital}

Pentobarbital is a medium duration barbiturate that provides potent sedation with no analgesic property. It can be administered via an oral or intravenous (IV) route. Following IV administration, the onset of action is $2-3$ minutes, with peak effects after $10-15$ minutes and a duration of action of 45-60 minutes due to rapid redistribution [25]. Following oral administration using an IV formulation of pentobarbital, sedation begins at 20-30 minutes and lasts $60-90$ minutes $[16,26,27]$. The oral dose of 4-8 $\mathrm{mg} / \mathrm{kg}$ and IV dose of 2-3 mg/ $\mathrm{kg}$ (to a maximum 5-8 mg/ $/ \mathrm{kg}$ ) are required to achieve deep sedation. The sedation success rates of pentobarbital for MRI in children are $87.8 \%-99.5 \%$ for IV administration $[16,17,26-28]$ and $67 \%-99.7 \%$ for oral administration [26,29-31] with a trend towards increasing failure rates with increasing age and weight. Retrospective comparison analysis found that oral pentobarbital has comparable sedation success rate (99.5\% vs. $99.7 \%)$ and time to discharge and a lower rate of desaturation ( $0.2 \%$ vs. $0.9 \%)$ compared with IV pentobarbital in 2,164 infants undergoing CT or MRI [26]. Both oral and IV pentobarbital are as effective as oral chloral hydrate for providing sedation for pediatric MRI $[16,29]$. However, when compared to oral chloral hydrate, oral pentobarbital has the advantage of fewer respiratory events in infants, whereas IV pentobarbital has the disadvantage of a higher incidence of more paradoxical reaction and major motion artifacts and prolonged recovery despite the advantage of earlier onset in children. Children with neurodevelopmental disability have similar dose requirements for pentobarbital but more respiratory adverse events and hypoxemia during MRI scans $[27,32,33]$.

Pentobarbital is associated with adverse reactions such as oxygen desaturation, nausea and vomiting, paradoxical hyperreactivity, respiratory depression, agitation, and prolonged sedation $[16,17,26-29,31]$. Airway obstruction is more likely to occur in infants. Oral pentobarbital results in a longer duration of action and less respiratory adverse events than IV administration [26]. Pentobarbital, like other barbiturates, is contraindicated in patients with porphyria.

\section{3) Midazolam}

Midazolam is a short-acting, water soluble benzodiazepine that has anxiolytic, sedative, amanestiec, and muscle relaxant properties. Its sedation mechanism is GABA-mediated enhancing chloride conductance in the central nervous system. Although midazolam can be given for sedation via mutiple routes, IV administration is preferred, if vascular access is present. The onset of action is typically $3-5$ minutes and lasts $30-45$ minutes with IV admini- 
station at $0.1 \mathrm{mg} / \mathrm{kg}$ with successive $0.05 \mathrm{mg} / \mathrm{kg}$ every 5 minutes (maximum $4 \mathrm{mg}$ ).

Although NICE recommends the consideration of midazolam as one of the first-line sedative drug for painless imaging procedures owing to a wide margin of safety [13], it is currently used as an adjuct sedative with either dexmedetomidine or ketamine rather than single primary agent for pediatric MRI [18,34-37] because of the high sedation failure rates, short duration of action, as well as frequent significant respiratory depression at deeply sedating doses $[38,39]$. However, coadministration of midazolam and other sedative agents, especially opioids, in children is not acceptable because of siginficant increases in cardiorespiratory depression and difficulty in predicting sedation effects [9]. Paradoxical excitement or delirium have been reported, usually following an IV dose, and may be managed with low-dose flumazenil.

Flumazenil is a benzodiazepine antagonist used to reverse sedation and/or respiratory depression caused by midazolam. Dosing starts at $0.01-0.02 \mathrm{mg} / \mathrm{kg}$ and can be repeated until adequate reversal of midazolam is noted (maximum $1 \mathrm{mg}$ ) [40]. As flumazenil is highly lipohlic, its onet of action is rapid (1-2 minutes) but duration of action is relatively short (30-45 minutes), so monitoring for resedation is necessary [41].

\section{4) Ketamine}

Ketamine is a phencyclidine analog and N-methyl-D-aspartate (NMDA) receptor antagonist that induces sedation, dissociative amnesia, and analgesia. Ketamine is used as a sedative for MRI because its analgesic component is not necessary for MRI. Administration routes are IV $(0.05-2 \mathrm{mg} / \mathrm{kg})$, intramuscular (IM; $4-5 \mathrm{mg})$, oral (5-6 mg/kg), and intranasal (5-10 mg/kg). IV use is preferable if IV access is available. The onset of action is rapid (1-2 minutes), the duration is brief (10-15 minutes) and the recovery is short (30-60 minutes) [42]. Ketamine is attractive for pediatric sedation because of its relatively short duration of action, multiple routes of administration, preservation of airway reflexes, and sympathomimetic properties including increase heart rates and blood pressure. Although sedation can be achieved with minimal respiratory depression, ketamine has various and lengthy adverse effect profiles including hallucination, emergence delirium, agitation, nausea and vomiting, hypersalivation, and laryngospasm, which may be distressing to both the child and parent. Often there are random movements of the extremities rendering this drug less than ideal for procedures where the patient must lie perfectly still during MRI scans. Thus, ketamine is used with a combination of other sedative agents to counterbalance the side effects and enhance the beneficial effects for each drug rather than as a sole sedative agent for MRI. Ketamine can counterbalance the cardiorespiratory depression effect of propofol and prolonged recovery of dexmedetomidine by reducing the dose requirements of each drug for MRI sedation in children [43-45].

\section{5) Dexmedetomidine}

Dexmedetomidine is a selective central $\alpha_{2}$ receptor agonist that has sedative, analgesic, anti-shivering sympatholytic, and anxiolytic properties. Its sedative mechanism results from a decrease in norepinephrine release from presynaptic neurons with the initiation of postsynaptic activation, attenuating central nervous system excitation. The most unique characteristic of dexmedetomidine is the preservation of respiratory drive with a low incidence of apnea, respiratory depression, or airway obstruction, which is highly advantageous in children who are prone to respiratory depression, such as those with neurodevelopmental disabilities or obstructive sleep apnea, while receiving sedation/analgesia [46-48].

Patients exhibit biphasic cardiovascular responses after IV administration of dexmedetomidine [49,50]: initial transient hypertension along with a baroreceptor-mediated decrease in heart rate by $\alpha_{2 B}$-adrenoreceptor vasoconstriction followed by hypotension and bradycardia (10\%-30\% from baseline) by $\alpha_{2 \mathrm{~A}}$-adrenoreceptor-mediated inhibition of central sympathetic outflow. The hypertensive effect and associated bradycardia can be reduced by infusion of loading dose over a 10 minutes period. Prehydration of $10 \mathrm{~mL} / \mathrm{kg}$ of normal saline solution is effective in decreasing the incidence of dexmedetomidine-related hypotension [51]. However, prophylaxis with glycopyrrolate for bradycardia is not routinely recommended because of transient severe hypertension [52]. Children are usually able to maintain systemic blood pressure with minimal impact on cardiac output and ultimately end organ perfusion.

Dexmedetomidine may be administered by oral, buccal, nasal, rectal, subcutaneous, IM, and IV routes. Dosing and bioavailability vary depending on the route of administration. When administered through IV, the average onset of sedation is 8.6 minutes with a recovery time of 41.4 minutes [53]. The rapid phase redistribution half-life is approximately 7 minutes, and the terminal elimination half-life is approximately 2 hours [54]. The success rate of sedation for pediatric MRI ranges from $83.3 \%$ with a $1 \mu \mathrm{g} / \mathrm{kg}$ bolus followed by $0.5 \mu \mathrm{g} / \mathrm{kg} / \mathrm{hr}$ infusion to $98 \%$ with a $3 \mu \mathrm{g} / \mathrm{kg}$ bolus followed by $2 \mu \mathrm{g} / \mathrm{kg} / \mathrm{hr}$ infusion [47,53]. Buccal (a mean of $2.20 \pm 0.38 \mu \mathrm{g} / \mathrm{kg})$ and intranasal $(3 \mu \mathrm{g} / \mathrm{kg})$ administration of dexmedetomidine may be useful in children with difficult IV cannulation, but their success rates of sedation for MRI are lower than IV administration and more sedative supplementation is required than IV administration $[34,35,55,56]$. Generally, a lack of respiratory depression combined with a relatively short half-life 
makes dexmedetomidine a useful single sedative agent for an ambulatory pediatric MRI setting. However, in spite of a similar success rate, it has slower onset and longer recovery compared to propofol in children undergoing MRI [54,57,58].

With the evolution of more complex MRI studies, dexmedetomidine is preferred to propofol for magnetoencephalography scans, which are employed for presurgical planning with intractable epilepsy due to the preservation of epileptiform activity [59]. The MRI sleep study is a relatively new imaging technique for the evaluation of obstructive sleep apnea. Minimal respiratory depression of dexmedetomidine decreased the use of artificial and manual airway supports such as the chin lift and shoulder roll, which can artificially alter the MRI results [60].

\section{Anesthetic agents}

\section{1) Propofol}

Propofol (2,6-diisopropylphenyl) is a potent IV anesthetic agent that has hypnotic but no analgesic properties via the potentiation of $\mathrm{GABA}_{\mathrm{A}}$ receptors and inhibition of NMDA receptors. Unlike with other sedative agents, propofol use is limited to the IV route. Propofol has a fast onset of action (10-50 seconds) and short distribution half-life (approximately 9 minutes in the pediatric population) [60]. Deep sedation is typically induced with a bolus dose of $1-3 \mathrm{mg} / \mathrm{kg}$ and $0.5-1 \mathrm{mg} / \mathrm{kg}$ supplementation every $1-2 \mathrm{~min}$ utes [61]. Higher dosing is often required for younger pediatric patients because of their higher volume of distribution, shorter elimination half-life, and higher plasma clearance [62]. A single dose or intermittent bolus doses of propofol may be suitable for brief procedures ( $<30$ minutes) [63], but continuous infusion of $2-5 \mathrm{mg} / \mathrm{kg} / \mathrm{hr}$ rather than intermittent administration is recommended for longer procedures [64] in children undergoing MRI. The use of MR-compatible infusion pumps allows for consistent maintenance of accurate dosing and reduces the amount of propofol need to achieve adequate and safe sedation in children undergoing MRI [65]. Although propofol is easily titratable, its narrow therapeutic margin combined with ultra-short-acting pharmacokinetic profiles is associated with the rapid progression of sedation levels leading to general anesthesia.

Because of its rapid onset, short recovery time, antiemetic properties, and low incidence of emergence delirium, propofol has gained popularity as a primary sole sedative agent for MRI in children. Compared to most other sedative regimens, propofol provides the shortest onset and recovery and a high sedation success rate for pediatric MRI [66-70]. However, propofol commonly causes hypotension and dose-dependent respiratory depression including hypoventilation, apnea, and airway obstruction, which may be exaggerated with concomitant opioid use [27,71-73]. Sedation providers must monitor the respiratory rate and et $\mathrm{CO}_{2}$ in children receiving propofol sedation. As mentioned above, coadministration of ketamine may be an option to counterbalance propofol-induced cardiorespiratory depression [45]. Pain during peripheral IV injection can be distressing to the parent and child but may be limited with low-dose lidocaine, fentanyl, or ketamine pretreatment [74]. Because propofol contains egg lecithin, patients with a history of egg allergy are at increased risk of an allergic reaction to propofol [75]. Because of its rapid acting and reliable titration of drug concentration, propofol is also used for general anesthesia with spontaneous ventilation, endotracheal intubation, or laryngeal mask airway (LMA) for MRI in children [76-78].

\section{2) Sevoflurane}

Generally deep sedation with spontaneous ventilation is preferred for MRI because of limited medical resources (mechanical ventilation and longer surveillance period). However, general anesthesia for MRI is indicated in select children with congenital heart defects or airway abnormalities, long-duration scans for staging investigations of malignancies, or those who have had previous sedation failure. Some MRI scans (cardiac, thoracic, or abdominal) require breath-holding to obtain adequate images. In such cases requiring the need for a secure airway, it is necessary to control airway with LMA or endotracheal intubation and deliver general anesthesia.

Sevoflurane is the inhalational agent of choice in children due to its lack of airway irritability and ability to provide stable hemodynamic function, together with its rapid onset and offset. Sevoflurane has been successfully used in newborns and infants with a maximum vaporizer setting of 4 vol\% for MRI $[79,80]$. Sevoflurane anesthesia provides higher success rates (92\% vs. $80 \%)$ and faster onset and recovery, but a higher incidence of emergence delirium than propofol anesthesia in children undergoing MRI $[70,76]$. Major airway-related adverse events such as respiratory apnea and severe airway obstruction occurred in $0.4 \%$ of children, while preterm infants are at higher risk compared to term infants after sevoflurane anesthesia for MRI [81]. Positive pressure ventilation with endotracheal intubation or LMA may result in more extensive atelectasis in children after MRI compared to spontaneous ventilation in children receiving sevoflurane-based anesthesia $[78,82]$.

Sevoflurane-based anesthesia is also reported to be highly feasible and safe in children with neuropsychiatric disorders undergoing MRI. Mongodi et al. [83] found that induction and maintenance of sevoflurane anesthesia inhaled by a reservoir bag mask at 8.0 and 2.5 vol\%, respectively, provides a median time of $15 \mathrm{~min}$ - 
utes for full recovery and lower rates of mechanical ventilation compared to other pharmacological approaches in retrospective analysis of data of 10 years at a single center. They identified children with an American Society of Anesthesiologists (ASA) score $>1$, male sex, prolonged procedures, and neuromuscular diseases as higher risk for general and respiratory complications in this population.

\section{Special consideration for pediatric drug use and development}

Many of the drugs used for sedation and analgesia in children are not approved by the Ministry of Food and Drug Safety (MFDS), formerly the Korean Food and Drug Administration (KFDA), for use in children under certain ages (e.g., fentanyl $<2$ years; remifentanil $<1$ year; propofol $<3$ years for anesthesia and $<18$ years for sedation; and dexmedetomidine $<18$ years of age). The lack of MFDS approval does not imply that a drug can/should not be used; rather, it means that pharmaceutical manufacturers never carried out the appropriate research to gain MFDS approval. Off-label use of drugs for sedation of children has grown exponentially prior to the development of well-controlled clinical trials in the pediatric population. A number of legislative changes are intended to improve drug labeling for safe and efficacious sedation in children $[84,85]$.

\section{Conclusion}

As the need for deep sedation and general anesthesia for children in an MRI suite continues to expand, anesthesiologists continue to be frequently requested to provide anesthesia services for these venues. The choice of agent and technique used for sedation or general anesthesia reflects the experience of the sedation provider, potential constraints imposed by the patient and procedure, availability of appropriate monitoring equipment, and institutional policies in place.

The use of traditional sedative agents such as pentobarbital and chloral hydrate has decreased due to long onset and recovery. Midazolam and ketamine are preferred as the adjunct rather than single use to counterbalance adverse events of other sedative agent. Currently, the use of propofol with high effectiveness and rapid recovery and dexmedetomidine with respiratory drive preservation have increased as the single agent for deep sedation and general anesthesia in children undergoing ambulatory MRI.

To provide the most effective, efficient, and safe sedation and anesthesia for children, the anesthesia service team should be familiar with MRI-specific safety issues and the requirements of op- timal quality images for precise diagnosis before induction. Further improvements of quality and cost effectiveness with new promising drugs are also necessary.

\section{Acknowledgments}

\section{Conflicts of interest}

No potential conflict of interest relevant to this article was reported.

\section{ORCID}

Sung Mee Jung, https://orcid.org/0000-0001-5602-9011

\section{References}

1. Uffman JC, Tumin D, Raman V, Thung A, Adler B, Tobias JD. MRI utilization and the associated use of sedation and anesthesia in a pediatric ACO.J Am Coll Radiol 2017;14:924-30.

2. Wachtel RE, Dexter F, Dow AJ. Growth rates in pediatric diagnostic imaging and sedation. Anesth Analg 2009;108:1616-21.

3. Dial S, Silver P, Bock K, Sagy M. Pediatric sedation for procedures titrated to a desired degree of immobility results in unpredictable depth of sedation. Pediatr Emerg Care 2001;17:41420.

4. Kaila R, Chen X, Kannikeswaran N. Postdischarge adverse events related to sedation for diagnostic imaging in children. Pediatr Emerg Care 2012;28:796-801.

5. Committee on Quality Management and Departmental Administration. Continuum of depth of sedation: definition of general anesthesia and levels of sedation/analgesia [Internet]. Schaumburg, IL: American Society of Anesthesiologists; 2019 [cited 2020 Mar 20]. https://www.asahq.org/standards-and-guidelines/continuum-of-depth-of-sedation-definition-of-general-anesthesia-and-levels-of-sedationanalgesia.

6. Cote CJ, Wilson S; American Academy of Pediatrics; American Academy of Pediatric Dentistry. Guidelines for monitoring and management of pediatric patients before, during, and after sedation for diagnostic and therapeutic procedures. Pediatrics 2019;143:e20191000.

7. Nedoma J, Fajkus M, Martinek R, Nazeran H. Vital sign monitoring and cardiac triggering at 1.5 tesla: a practical solution by an MR-ballistocardiography fiber-optic sensor. Sensors (Basel) 2019; 19:470.

8. Kamat PP, McCracken CE, Gillespie SE, Fortenberry JD, Stockwell JA, Cravero JP, et al. Pediatric critical care physician-administered procedural sedation using propofol: a report from the Pediatric Sedation Research Consortium Database. Pediatr Crit 
Care Med 2015;16:11-20.

9. Sanborn PA, Michna E, Zurakowski D, Burrows PE, Fontaine PJ, Connor L, et al. Adverse cardiovascular and respiratory events during sedation of pediatric patients for imaging examinations. Radiology 2005;237:288-94.

10. Mayers DJ, Hindmarsh KW, Sankaran K, Gorecki DK, Kasian GF. Chloral hydrate disposition following single-dose administration to critically ill neonates and children. Dev Pharmacol Ther 1991;16:71-7.

11. Litman RS, Soin K, Salam A. Chloral hydrate sedation in term and preterm infants: an analysis of efficacy and complications. Anesth Analg 2010;110:739-46.

12. Ratnapalan S. Chloral hydrate sedation in children. Clin Pediatr (Phila) 2014;53:933-6.

13. National Institute for Health and Care Excellence (NICE). Sedation in under 19s: using sedation for diagnostic and therapeutic procedures (Clinical guideline CG112) [Internet]. London (UK): NICE; 2010 [cited 2020 Mar 20]. https://www.nice. org.uk/guidance/cg112.

14. Low E, O'Driscoll M, MacEneaney P, O'Mahony O. Sedation with oral chloral hydrate in children undergoing MRI scanning. Ir Med J 2008;101:80-2.

15. Lee YJ, Kim DK, Kwak YH, Kim HB, Park JH, Jung JH. Analysis of the appropriate age and weight for pediatric patient sedation for magnetic resonance imaging. Am J Emerg Med 2012;30: 1189-95.

16. Malviya S, Voepel-Lewis T, Tait AR, Reynolds PI, Gujar SK, Gebarski SS, et al. Pentobarbital vs chloral hydrate for sedation of children undergoing MRI: efficacy and recovery characteristics. Paediatr Anaesth 2004;14:589-95.

17. Dalal PG, Murray D, Cox T, McAllister J, Snider R. Sedation and anesthesia protocols used for magnetic resonance imaging studies in infants: provider and pharmacologic considerations. Anesth Analg 2006;103:863-8.

18. Cortellazzi P, Lamperti M, Minati L, Falcone C, Pantaleoni C, Caldiroli D. Sedation of neurologically impaired children undergoing MRI: a sequential approach. Paediatr Anaesth 2007; 17:630-6.

19. Delgado J, Toro R, Rascovsky S, Arango A, Angel GJ, Calvo V, et al. Chloral hydrate in pediatric magnetic resonance imaging: evaluation of a 10-year sedation experience administered by radiologists. Pediatr Radiol 2015;45:108-14.

20. Greenberg SB, Faerber EN, Aspinall CL, Adams RC. High-dose chloral hydrate sedation for children undergoing MR imaging: safety and efficacy in relation to age. AJR Am J Roentgenol 1993;161:639-41.

21. Finnemore A, Toulmin H, Merchant N, Arichi T, Tusor N, Cox
$D$, et al. Chloral hydrate sedation for magnetic resonance imaging in newborn infants. Paediatr Anaesth 2014;24:190-5.

22. Mace SE, Brown LA, Francis L, Godwin SA, Hahn SA, Howard PK, et al. Clinical policy: critical issues in the sedation of pediatric patients in the emergency department. Ann Emerg Med 2008;51:378-99.

23. Lipshitz M, Marino BL, Sanders ST. Chloral hydrate side effects in young children: causes and management. Heart Lung 1993; 22:408-14.

24. Schulte-Uentrop L, Goepfert MS. Anaesthesia or sedation for MRI in children. Curr Opin Anaesthesiol 2010;23:513-7.

25. Ehrnebo M. Pharmacokinetics and distribution properties of pentobarbital in humans following oral and intravenous administration.J Pharm Sci 1974;63:1114-8.

26. Mason KP, Zurakowski D, Connor L, Karian VE, Fontaine PJ, Sanborn PA, et al. Infant sedation for MR imaging and CT: oral versus intravenous pentobarbital. Radiology 2004;233:723-8.

27. Mallory MD, Baxter AL, Kost SI; Pediatric Sedation Research Consortium. Propofol vs pentobarbital for sedation of children undergoing magnetic resonance imaging: results from the Pediatric Sedation Research Consortium. Paediatr Anaesth 2009; 19:601-11.

28. Greenberg SB, Adams RC, Aspinall CL. Initial experience with intravenous pentobarbital sedation for children undergoing MRI at a tertiary care pediatric hospital: the learning curve. Pediatr Radiol 2000;30:689-91.

29. Mason KP, Sanborn P, Zurakowski D, Karian VE, Connor L, Fontaine PJ, et al. Superiority of pentobarbital versus chloral hydrate for sedation in infants during imaging. Radiology 2004; 230:537-42.

30. Schlatter J, Kabiche S, Sellier N, Fontan JE. Oral pentobarbital suspension for children sedation during MR imaging. Ann Pharm Fr 2018;76:286-90.

31. Rooks VJ, Chung T, Connor L, Zurakowski D, Hoffer FA, Mason KP, et al. Comparison of oral pentobarbital sodium (nembutal) and oral chloral hydrate for sedation of infants during radiologic imaging: preliminary results. AJR Am J Roentgenol 2003;180:1125-8.

32. Ross AK, Hazlett HC, Garrett NT, Wilkerson C, Piven J. Moderate sedation for MRI in young children with autism. Pediatr Radiol 2005;35:867-71.

33. Kannikeswaran N, Chen X, Sethuraman U. Utility of endtidal carbon dioxide monitoring in detection of hypoxia during sedation for brain magnetic resonance imaging in children with developmental disabilities. Paediatr Anaesth 2011;21:1241-6.

34. Boriosi JP, EickhoffJC, Hollman GA. Safety and efficacy of buccal dexmedetomidine for MRI sedation in school-aged children. 
Hosp Pediatr 2019;9:348-54.

35. Sulton C, Kamat P, Mallory M, Reynolds J. The use of intranasal dexmedetomidine and midazolam for sedated magnetic resonance imaging in children: a report from the Pediatric Sedation Research Consortium. Pediatr Emerg Care 2020;36:138-42.

36. Ibrahim M. A prospective, randomized, double blinded comparison of intranasal dexmedetomodine vs intranasal ketamine in combination with intravenous midazolam for procedural sedation in school aged children undergoing MRI. Anesth Essays Res 2014;8:179-86.

37. Pershad J, Wan J, Anghelescu DL. Comparison of propofol with pentobarbital/midazolam/fentanyl sedation for magnetic resonance imaging of the brain in children. Pediatrics 2007; 120:e629-36.

38. D'Agostino J, Terndrup TE. Chloral hydrate versus midazolam for sedation of children for neuroimaging: a randomized clinical trial. Pediatr Emerg Care 2000;16:1-4.

39. Rupprecht T, Kuth R, Bowing B, Gerling S, Wagner M, Rascher $\mathrm{W}$. Sedation and monitoring of paediatric patients undergoing open low-field MRI. Acta Paediatr 2000;89:1077-81.

40. Mazurek MS. Sedation and analgesia for procedures outside the operating room. Semin Pediatr Surg 2004;13:166-73.

41. Shannon M, Albers G, Burkhart K, Liebelt E, Kelley M, McCubbin MM, et al. Safety and efficacy of flumazenil in the reversal of benzodiazepine-induced conscious sedation. The Flumazenil Pediatric Study Group. J Pediatr 1997;131:582-6.

42. White PF, Way WL, Trevor AJ. Ketamine: its pharmacology and therapeutic uses. Anesthesiology 1982;56:119-36.

43. Kim JG, Lee HB, Jeon SB. Combination of dexmedetomidine and ketamine for magnetic resonance imaging sedation. Front Neurol 2019;10:416.

44. Tomatir E, Atalay H, Gurses E, Erbay H, Bozkurt P. Effects of low dose ketamine before induction on propofol anesthesia for pediatric magnetic resonance imaging. Paediatr Anaesth 2004; 14:845-50.

45. Schmitz A, Weiss M, Kellenberger C, O'Gorman Tuura R, Klaghofer R, Scheer I, et al. Sedation for magnetic resonance imaging using propofol with or without ketamine at induction in pediatrics: a prospective randomized double-blinded study. Paediatr Anaesth 2018;28:264-74.

46. Mahmoud M, Mason KP. Dexmedetomidine: review, update, and future considerations of paediatric perioperative and periprocedural applications and limitations. Br J Anaesth 2015; 115:171-82.

47. Mahmoud M, Gunter J, Donnelly LF, Wang Y, Nick TG, Sadhasivam S. A comparison of dexmedetomidine with propofol for magnetic resonance imaging sleep studies in children. Anesth
Analg 2009; 109:745-53.

48. Sriganesh K, Saini J, Theerth K, Venkataramaiah S. Airway dimensions in children with neurological disabilities during dexmedetomidine and propofol sedation for magnetic resonance imaging study. TurkJ Anaesthesiol Reanim 2018;46:214-21.

49. Bloor BC, Ward DS, Belleville JP, Maze M. Effects of intravenous dexmedetomidine in humans. II. Hemodynamic changes. Anesthesiology 1992;77:1134-42.

50. Philipp M, Brede M, Hein L. Physiological significance of alpha(2)-adrenergic receptor subtype diversity: one receptor is not enough. Am J Physiol Regul Integr Comp Physiol 2002; 283:R287-95.

51. Mason KP, Turner DP, Houle TT, Fontaine PJ, Lerman J. Hemodynamic response to fluid management in children undergoing dexmedetomidine sedation for MRI. AJR Am J Roentgenol 2014;202:W574-9.

52. Mason KP, Zgleszewski S, Forman RE, Stark C, DiNardo JA. An exaggerated hypertensive response to glycopyrrolate therapy for bradycardia associated with high-dose dexmedetomidine. Anesth Analg 2009;108:906-8.

53. Mason KP, Zurakowski D, Zgleszewski SE, Robson CD, Carrier M, Hickey PR, et al. High dose dexmedetomidine as the sole sedative for pediatric MRI. Paediatr Anaesth 2008; 18:403-11.

54. Ebert TJ, Hall JE, Barney JA, Uhrich TD, Colinco MD. The effects of increasing plasma concentrations of dexmedetomidine in humans. Anesthesiology 2000;93:382-94.

55. Boriosi JP, EickhoffJC, Hollman GA. Safety and efficacy of buccal dexmedetomidine for MRI sedation in school-aged children. Hosp Pediatr 2019;9:348-54.

56. Tug A, Hanci A, Turk HS, Aybey F, Isil CT, Sayin P, et al. Comparison of two different intranasal doses of dexmedetomidine in children for magnetic resonance imaging sedation. Paediatr Drugs 2015;17:479-85.

57. Teshome G, Belani K, Braun JL, Constantine DR, Gattu RK, Lichenstein R. Comparison of dexmedetomidine with pentobarbital for pediatric MRI sedation. Hosp Pediatr 2014;4:360_ 5.

58. Belleville JP, Ward DS, Bloor BC, Maze M. Effects of intravenous dexmedetomidine in humans. I. Sedation, ventilation, and metabolic rate. Anesthesiology 1992; 77:1125-33.

59. Konig MW, Mahmoud MA, Fujiwara H, Hemasilpin N, Lee $\mathrm{KH}$, Rose DF. Influence of anesthetic management on quality of magnetoencephalography scan data in pediatric patients: a case series. Paediatr Anaesth 2009; 19:507-12.

60. Roback MG, Carlson DW, Babl FE, Kennedy RM. Update on pharmacological management of procedural sedation for children. Curr Opin Anaesthesiol 2016;29(Suppl 1):S21-35. 
61. Machata AM, Willschke H, Kabon B, Kettner SC, Marhofer P. Propofol-based sedation regimen for infants and children undergoing ambulatory magnetic resonance imaging. Br J Anaesth 2008;101:239-43.

62. Gutmann A, Pessenbacher K, Gschanes A, Eggenreich U, Wargenau M, Toller W. Propofol anesthesia in spontaneously breathing children undergoing magnetic resonance imaging: comparison of two propofol emulsions. Paediatr Anaesth 2006; 16:266-74.

63. Cho JE, Kim WO, Chang DJ, Choi EM, Oh SY, Kil HK. Titrated propofol induction vs. continuous infusion in children undergoing magnetic resonance imaging. Acta Anaesthesiol Scand 2010;54:453-7.

64. Hassan NE, Betz BW, Cole MR, Wincek J, Reischman D, Sanfilippo DJ, et al. Randomized controlled trial for intermittent versus continuous propofol sedation for pediatric brain and spine magnetic resonance imaging studies. Pediatr Crit Care Med 2011;12:e262-5.

65. Abdallah C, Hannallah R, Patel K. MR-compatible pumps versus manual titration of propofol for pediatric sedation. J Med Eng Technol 2010;34:443-7.

66. Zhou Q, Shen L, Zhang X, Li J, Tang Y. Dexmedetomidine versus propofol on the sedation of pediatric patients during magnetic resonance imaging (MRI) scanning: a meta-analysis of current studies. Oncotarget 2017;8:102468-73.

67. Ahmed SS, Unland TL, Slaven JE, Nitu ME. Dexmedetomidine versus propofol: is one better than the other for MRI sedation in children? J Pediatr Intensive Care 2017;6:117-22.

68. Fang H, Yang L, Wang X, Zhu H. Clinical efficacy of dexmedetomidine versus propofol in children undergoing magnetic resonance imaging: a meta-analysis. Int J Clin Exp Med 2015;8: 11881-9.

69. Wu J, Mahmoud M, Schmitt M, Hossain M, Kurth D. Comparison of propofol and dexmedetomedine techniques in children undergoing magnetic resonance imaging. Paediatr Anaesth 2014;24:813-8.

70. Bryan YF, Hoke LK, Taghon TA, Nick TG, Wang Y, Kennedy $\mathrm{SM}$, et al. A randomized trial comparing sevoflurane and propofol in children undergoing MRI scans. Paediatr Anaesth 2009; 19:672-81.

71. Mallory MD, Baxter AL, Yanosky DJ, Cravero JP; Pediatric Sedation Research Consortium. Emergency physician-administered propofol sedation: a report on 25,433 sedations from the pediatric sedation research consortium. Ann Emerg Med 2011; $57: 462-8$

72. Cravero JP, Beach ML, Blike GT, Gallagher SM, Hertzog JH; Pediatric Sedation Research Consortium. The incidence and nature of adverse events during pediatric sedation/anesthesia with propofol for procedures outside the operating room: a report from the Pediatric Sedation Research Consortium. Anesth Analg 2009; 108:795-804.

73. Srinivasan M, Turmelle M, Depalma LM, Mao J, Carlson DW. Procedural sedation for diagnostic imaging in children by pediatric hospitalists using propofol: analysis of the nature, frequen$\mathrm{cy}$, and predictors of adverse events and interventions. J Pediatr 2012;160:801-6.

74. Picard P, Tramer MR. Prevention of pain on injection with propofol: a equantitative systematic review. Anesth Analg 2000;90:963-9.

75. Murphy A, Campbell DE, Baines D, Mehr S. Allergic reactions to propofol in egg-allergic children. Anesth Analg 2011;113: $140-4$.

76. Kol IO, Egilmez H, Kaygusuz K, Gursoy S, Mimaroglu C. Open-label, prospective, randomized comparison of propofol and sevoflurane for laryngeal mask anesthesia for magnetic resonance imaging in pediatric patients. Clin Ther 2008;30:17581.

77. Tsui BC, Wagner A, Usher AG, Cave DA, Tang C. Combined propofol and remifentanil intravenous anesthesia for pediatric patients undergoing magnetic resonance imaging. Paediatr Anaesth 2005;15:397-401.

78. Lutterbey G, Wattjes MP, Doerr D, Fischer NJ, Gieseke J Jr, Schild HH. Atelectasis in children undergoing either propofol infusion or positive pressure ventilation anesthesia for magnetic resonance imaging. Paediatr Anaesth 2007;17:121-5.

79. Sury MR, Harker H, Thomas ML. Sevoflurane sedation in infants undergoing MRI: a preliminary report. Paediatr Anaesth 2005; 15:16-22.

80. De Sanctis Briggs V. Magnetic resonance imaging under sedation in newborns and infants: a study of 640 cases using sevoflurane. Paediatr Anaesth 2005;15:9-15.

81. Lei H, Chao L, Miao T, Shen Ling L, Yan Ying P, Xiao Han P, et al. Serious airway-related adverse events with sevoflurane anesthesia via facemask for magnetic resonance imaging in 7129 pediatric patients: a retrospective study. Paediatr Anaesth 2019; 29:635-9.

82. Blitman NM, Lee HK, Jain VR, Vicencio AG, Girshin M, Haramati LB. Pulmonary atelectasis in children anesthetized for cardiothoracic MR: evaluation of risk factors. J Comput Assist Tomogr 2007;31:789-94.

83. Mongodi S, Ottonello G, Viggiano R, Borrelli P, Orcesi S, Pichiecchio A, et al. Ten-year experience with standardized non-operating room anesthesia with Sevoflurane for MRI in children affected by neuropsychiatric disorders. BMC Anesthesiol 
2019;19:235.

84. Schultheis LW, Mathis LL, Roca RA, Simone AF, Hertz SH, Rappaport BA. Pediatric drug development in anesthesiology: an FDA perspective. Anesth Analg 2006;103:49-51.
85. Gore R, Chugh PK, Tripathi CD, Lhamo Y, Gautam S. Pediatric off-label and unlicensed drug use and its implications. Curr Clin Pharmacol 2017; 12:18-25. 